\title{
Research Concerning the Use of Different Mulching Methods on Lavender
}

\author{
Zsolt SZEKELY-VARGA ${ }^{1}$, Monica Tereza BOSCAIU NEAGU ${ }^{2}$ and Maria CANTOR ${ }^{1 *}$ \\ ${ }^{1}$ Department of Horticulture and Landscape Design. University of Agricultural Sciences and \\ Veterinary Medicine, Cluj-Napoca, 3-5 Mănăstur St., Romania \\ ${ }^{2}$ Mediterranean Agroforestal Institute, Universitat Politècnica de València, Camí de Vera, Spain \\ *corresponding author: marcantor@yahoo.com
}

BulletinUASVM Horticulture 77(1) / 2020

Print ISSN 1843-5254, Electronic ISSN 1843-5394

DOI:10.15835/buasvmcn-hort: 2019.0011

\begin{abstract}
Lavandula angustifolia Mill. is a highly appreciated and precious shrub worldwide due to the high essential oil content and properties. The aim of this research was to determine the influence of organic farming on lavender production. The experiment was carried out during a 2-years period (2018 - 2019) at the University of Agricultural Sciences and Veterinary Medicine Cluj-Napoca, in the experimental field. The biological material used in this experiment was represented by two Lavandula angustifolia Mill. cultivars ('Codreanca' and 'Sevtopolis'). The observations consisted of the evaluation of weed density, two times/year, at the beginning and at the end of the flowering period of the lavender plants. As expected, the highest weed density was in the control treatment followed by the straw/hay treatment while the lowest weed density was recorded in the treatment with the mulch foil.
\end{abstract}

Keywords: lavender, mulching, mulching foil, sustainable, straw/hay, weed control

\section{Introduction}

Weeds were found in the agricultural field since humanity have began cultivating plants for food and fiber (Price, 2012). In the 60's it was a movement called 'Green Revolution' that would solve practically the problem of feeding the entire world, everybody thought that the agriculture does not have anything new to provide. This was a set of research technology transfer initiative, which resulted in controlled water-supply, adaptation of new technologies, chemical and agro-chemical fertilizers and new methods of cultivation. After the green revolution had finished, the agriculture fields faced new challenges to cope with, like generalization of modern crops, achieving record yields, promoting non-conventional forms of agriculture (biological, organic) (Stan,
2010). Sustainable forms of agriculture ensure ecosystem conservation and economical efficiency in the circumstances and it is promoting the unconventional/organic biological or ecological agriculture (Gary, 2004). According to Cezar et al. (2015) weed control is one of the most important management practices in the production systems and it can highly influence the agriculture production and also can have an impact on the environment. Mulching plays an important role in medicinal and aromatic plant cultivation, weed control and plant growth (Fontana et al., 2006). Lavandula angustifolia Mill. is a highly appreciated and precious plant due to the high essential oil content and properties (Berringer Bader, 2012), which is used for treating many human diseases such as anxiety, hypnosis, cold, with anti- 
inflammatory, antiseptic role and it is also used in the cosmetical field for soap, cream perfume (Toma, 2009). Also for the use of the lavender essential oil in the medicinal and cosmetic industry it is recommended to have a lavender field which is not contaminated with chemicals from herbicides. Regarding this important benefits of lavender, high quality essential oil should be obtained considering that when harvesting the lavender flower stem, the weeds could pollute the essential oil (Hoeberechts et al., 2002).

The aim of this research was to determine the influence of the organic farming to have good results, quantitatively (a high vegetable raw material) and qualitatively (essential oil of the highest quality). For this purpose, the main objective of the research was to use different mulching types to reduce the weed occurance in the raw material composition leading to cleaner essential oil.

\section{Materials and methods}

The research was carried out for a period of 2-years and there were used two Lavandula angustifolia Mill. cultivars ('Codreanca' and 'Sevtopolis'). In this experiment unmulched (control), straw/hay and mulch foil variants were used. The experimental field had a $270 \mathrm{~m}^{2}$ agricultural land. This land was divided into two equal plots of $135 \mathrm{~m}^{2}$, which then were divided into four equal parcels of $33.75 \mathrm{~m}^{2}$ and on each plot were planted 30 lavender plants of the two cultivars. Then there have been applied the three experimental variants: control, straw/hay, mulching foil. Weed evaluation were made using a square frame of $0.6 \mathrm{~m} \times 0.6 \mathrm{~m}$. From each repetition one lavender was selected and coded as $V_{1}, V_{2}$, $V_{3}, V_{4}$. Weed density was evaluated by counting the weeds $/ \mathrm{m}^{2}$ of each species. Weed density was evaluated two times/year, at the beginning and at the end of the flowering period of the lavender plants.

The results were statistically interpreted using Paired Two Sample for Means t-Test $(<0.05)$, with Microsoft Excel program from the Microsoft Office package.

\section{Results and Discussion}

The main weeds that have counted were: Setaria viridis, Setaria glauca, Echinochloa crusgalli, Agropyrum repens, Amaranthus retroflexus,
Chenopodium album, Convolvulus arvensis, Xanthium italicum, Taraxacum offinale.

Figure 1 show the results of the first evaluation which was made in 16.07.2018. Statistically significant differences can be observed between the control, straw/hay and mulching foil treatments. At the 'Codreanca' cultivar the control treatment, without mulching presented the highest weed density compared to the other two treatments. Thus the average density for the control variant was $55.55 \%$, straw/hay variant $38.19 \%$ and the mulching foil version was $19.42 \%$ per $1 \mathrm{~m}^{2}$. Regarding 'Sevtopolis' cultivar, the highest weed density was in the control $52.20 \%$ per $1 \mathrm{~m}^{2}$, followed by the straw/hay $37.85 \%$ and the mulch foil $21.65 \%$ variants.

The second evaluation (Fig. 2) of weed density was made in 12.09.2018. At 'Codreanca' cultivar no statistically significant differences were found between the three treatments. The average weed density in the control variant was $42.35 \%$, in straw/hay variant $27.77 \%$ and in the variant with the mulching foil it was $20.83 \%$ per $1 \mathrm{~m}^{2}$. There were no statistically significant differences in the 'Sevtopolis' cultivar between control and straw/ hay treatment. On the other hand, the control and mulching foil are showing significant statistical differences. The average weed density was $41.22 \%$ in the control, $31.72 \%$ in the straw/hay treatment and $20.08 \%$ in the mulching foil.

The third weed density evaluation (Fig. 3) have been made in 10.06.2019. This time at 'Codreanca' cultivar were observed statistically significant differences between the control treatment and straw/hay, and also between the control and mulching foil. The average densities were: control $67.35 \%$, straw/hay $38.88 \%$ and the mulching foil $18.05 \%$. At 'Sevtopolis' cultivar no statistically significant differences were observed, thus the average density for the control was $61.3 \%$, straw/ hay treatment $29.16 \%$ and mulch foil $22.24 \%$.

The fourth evaluation of weed density (Fig. 4) was carried out in 02.09.2019. In this case the 'Codreanca' cultivar showed no statistically significant difference between the control $(29.16 \%)$ and the straw/hay (19.44\%) treatments. Between the control (29.16\%) and mulching foil $(11.10 \%)$ treatments statistically significant differences were recorded. At 'Sevtopolis' cultivar, between control and straw/hay treatments there are no statistically significant differences 

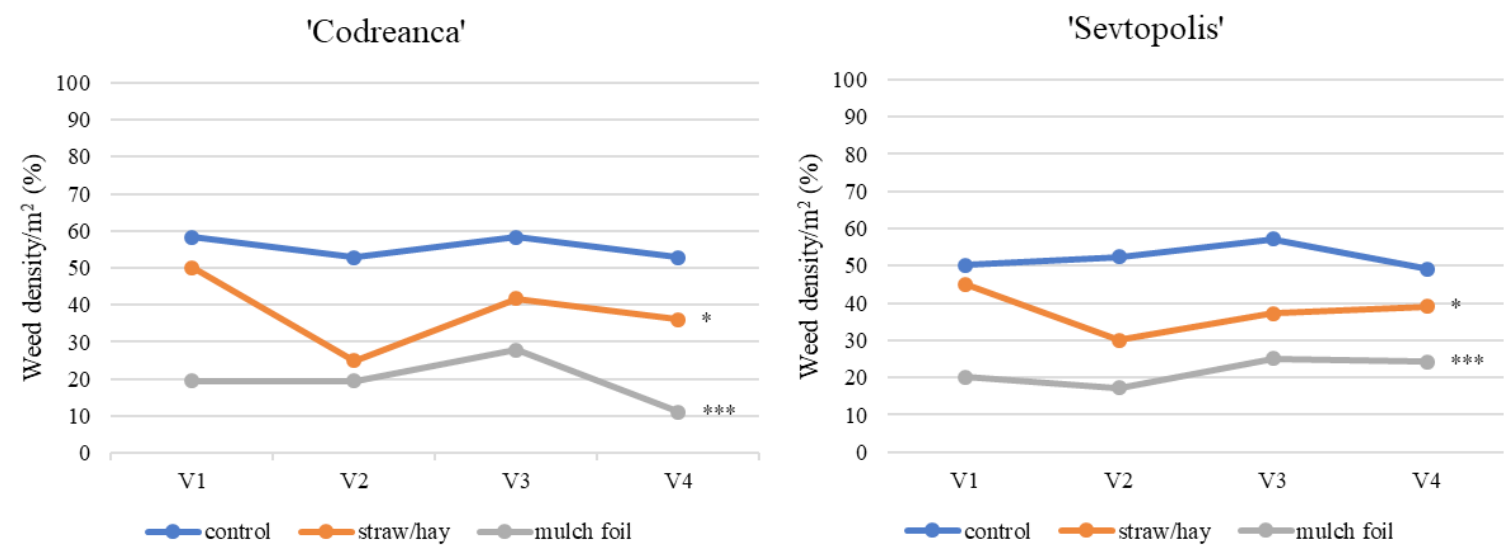

Figure 1. Evaluation of the weed density in 16.07.2018
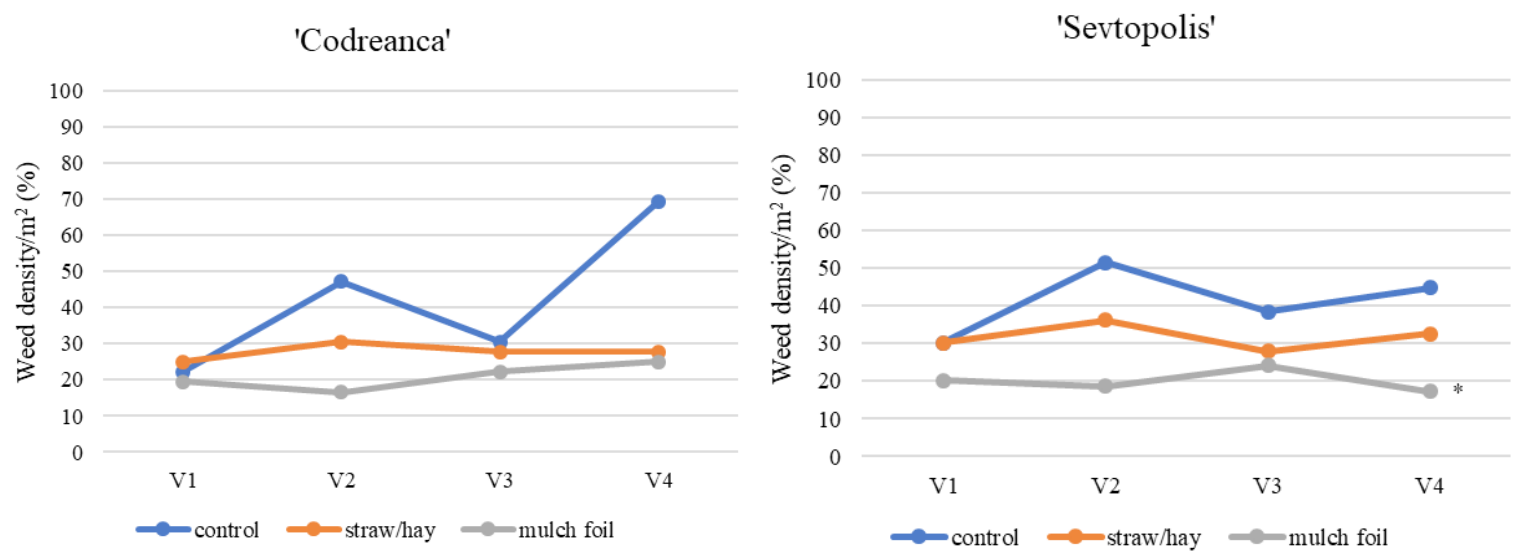

Figure 2. Evaluation of the weed density in 12.09.2018
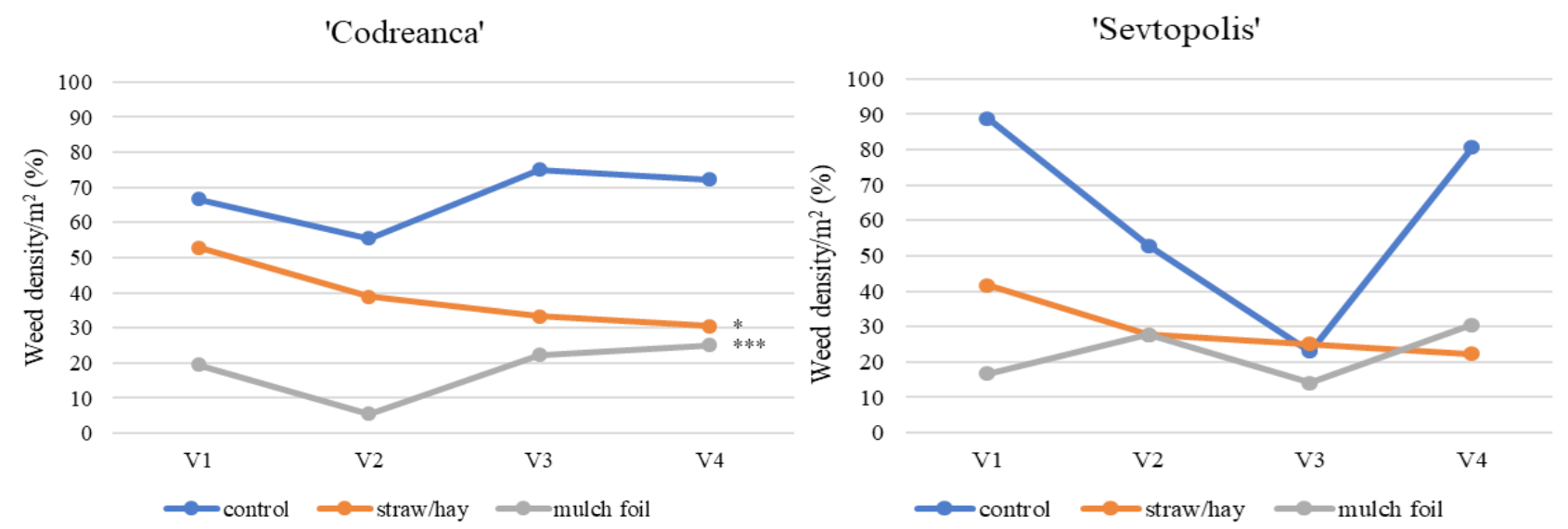

Figure 3. Evaluation of the weed density in 10.06.2019 

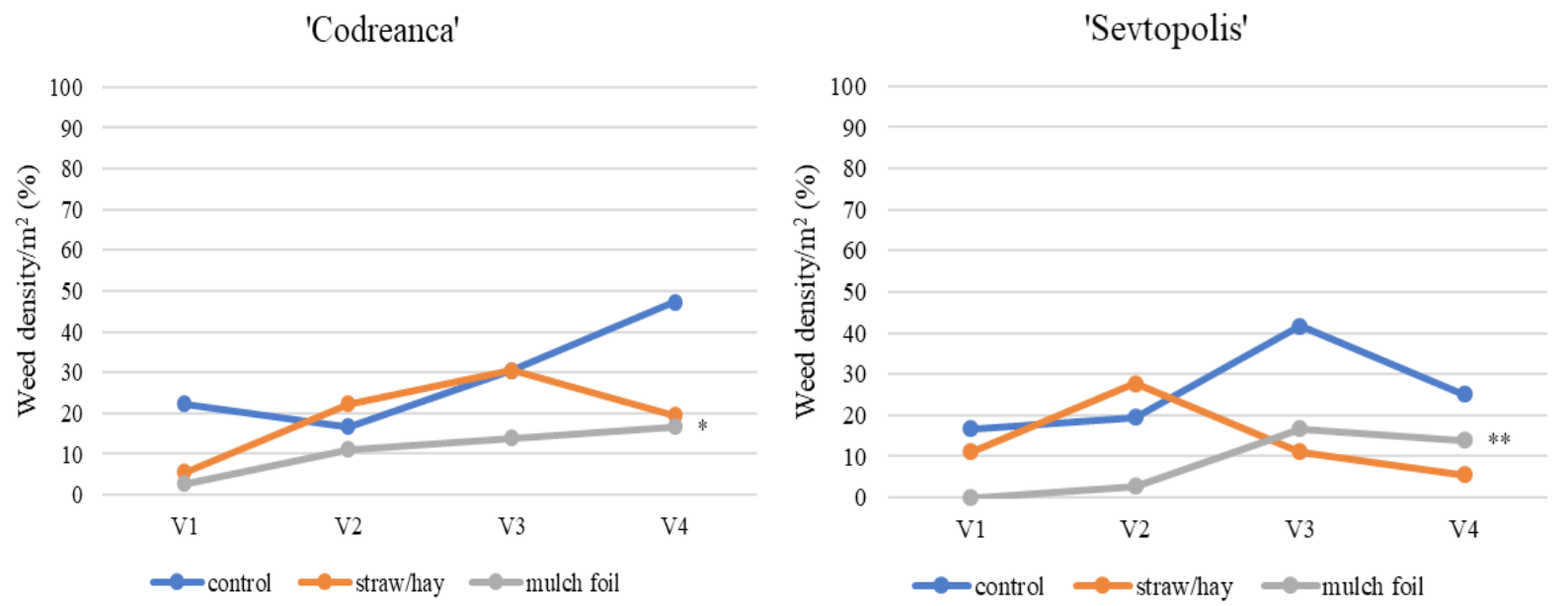

Figure 4. Evaluation of the weed density in 02.09.2019

observed. Between control and mulching foil treatments statistically significant differences were recorded. Average weed occurance: $25.69 \%$ in control, $13.88 \%$ in straw/hay and in the mulch foil is $8.32 \%$.

Our results are in accordance with Hoeberechts et al. (2002) research, where the mulching foil have had the same effects at the lavender and rosemary cultivation. Similar results were also obtained by Singh (2013), who proved that by adding mulch to rosemary it can be improved the content and the quality of the oil.

Campiglia et al. (2009) research results are similar, where the mulches have suppressed weeds in an average density of $80 \%$. In a research conducted by Radics and Szné Bognár (2002) concerning tomato and bean cultivation, the best weed control technique resulted was plastic and paper covering. Similar result were obtained by Mahajan et al. (2007), who proved that the plastic mulch accelerated early growth, height and fruiting of the baby corn and also gave a satisfactory weed control.

Massa et al. (2019) tested organic mulching and chemical herbicide effect on weed control, and in both cases the results were the same.

\section{Conclusion}

This research remarks the importance of using mulching materials and finding new techniques for their use in weed control in lavender cultivation, to make the fields less dependent on chemical weeding.
Our work has led us to conclude that, the highest weed density was in the control treatments followed by the straw/hay treatment and the lowest weed density was recorded in the treatment with the mulch foil. In the present research, we have demonstrated that weed control by mulching with foil reduces the average weed density to $20 \%$, compared to the straw/hay where the average weed density was $30-35 \%$ and the control (unmulched) variant with $50 \%$.

\section{References}

1. Berringer Bader S (2012). The lavender lover's handbook, Timber Press. London.

2. Campiglia E, Mancinelli R, Radicetti E, Caporali F (2010). Effect of cover crops and mulches on weed control and nitrogen fertilization in tomato (Lycopersicon esculentum Mill.). Crop Protection, 29(4): 354-363.

3. Cezar FA-J, Bruno HM, Vinicius YH, Carlos AH (2015). The role of weed and cover crops on soil and water conservation in a tropical region. In Pilipavicius $\mathrm{V}$ (Eds.), Weed Biology and Control (pp. 1). Lithuania: AvE4EvA.

4. Fontana E, Hoeberechts J, Nicola S (2006). Effect of mulching on medicinal and aromatic plants in organic farm guest houses. In I International Symposium on the Labiatae: Advances in Production, Biotechnology and Utilisation, 723 (pp. 405-410).

5. Gary C (2004). Evaluation, design and control of sustainable horticultural croping systems. Proc XXVI IHC - Sustainability of Horticultural Systems - ISHS.

6. Hoeberechts J, Nicola S, Fontana E (2002). Growth of lavender (Lavandula officinalis) and rosemary (Rosmarinus officinalis) in response to different 
mulches. In XXVI International Horticultural Congress: The future for medicinal and aromatic plants 629:245251.

7. Mahajan G, Sharda R, Kumar A, Sing KG (2007). Effect of plastic mulch on economizing irrigation water and weed control in baby corn sown by different methods. African Journal of Agricultural Research, 2(1): 19-26.

8. Massa D, Benvenuti S, Cacini S, Lazzereschi S, Burchi G (2019). Effect of hydro-compacting organic mulch on weed control and crop performance in the cultivation of three container-grown ornamental shrubs: Old solutions meet new insights. Scientia Horticulturae, 252: 260-267.

9. Price AJ (2012). Weed control. Croatia: InTech.

10. Radics L, Szné Bognár E (2002). Comparison of different mulching methods for weed control in organic green bean and tomato. In XXVI International Horticultural Congress: Sustainability of Horticultural Systems in the 21st Century. 638 (pp. 189-196).

11. Singh M (2013). Influence of organic mulching and nitrogen application on essential oil yield and nitrogen use efficiency of rosemary (Rosmarinus officinalis L.). Archives of Agronomy and Soil Science. 59(2): 273279.

12. STAN CI (2010). Improvement of vegetable and floriculture plants growing technology by using mulching and superabsorbents. Doctoral Thesis. Iasi.

13. TOMA F (2009). Floricultură si artă florală. Specii utilizate pentru decorul parcurilor si grădinilor. Ed. INVELMultimedia Bucuresti, vol. 4 (pp. 213-214). 